\title{
Sustainable Development and its Challenges in the Context of Global Economy
}

\author{
Robert JANIK \\ Technical University of Czestochowa, Faculty of Management
}

\begin{abstract}
The environment has been ravaged and overexploited by human beings almost from the dawn of civilization. However, no sooner that in the course of the industrial revolution did the extensive exploitation of the Earth 's resources, combined connected with the destruction of nature on a really great scale being a side-effect of economic activities, commence.

Along with the globalization process, and the spread of the business philosophy of "profit at any cost', the situation was becoming ever more serious. This as well as many ecological disasters caused by human activity made mankind aware of the "shape of dangers to come" and the need to counteract the degradation of the environment, which gave rise to various environment protection concepts. Among them, 'sustainable development", offering a well-balanced approach to the relationship between mankind and the environment, plays an essential role.

Sustainable development, which, meanwhile, has become a sui generis universal doctrine, is based upon three main pillars: social inclusion, economic growth and environment protection. According to the majority of public opinion, it is an adequate response to many contemporary challenges. However, it is not easy to implement its goals nowadays as there are many challenges, most of which are connected with the effects of catastrophes connected with climate changes, the scarcity of resources, soil and air contamination, social inequalities, political tensions, at times leading to wars, or business' selfish attitudes and nationalistic "'sacro egoismo"'.

To be effective, sustainable development must cover several key areas of mankind activity such as education, economy or health care. Decision-makers like entrepreneurs and managers can play an important role in this endeavour.

The purpose of this article is to holistically present the possibilities of implementing sustainable development concept in the context of relevant previous experiences and the current threats. This article fills the existing gap in research evidenced by the content of the literature of the subject.

Methodology approach: The specificity of this research rendered it necessary to use the documentary research method and historical research method.

Social implications: In the area of application, this article presents the conclusions resulting from it having become possible to sustainable development concept as well as possible difficulties in this respect. In this context, the role of human consciousness in finding the best solutions to the difficulties faced by all the stakeholders of implementing sustainable development concept was emphasized.
\end{abstract}

Key words: sustainable development, production, environment resources, globalization

\section{Introduction}

The economic activity of our species led to civilization development. Unfortunately, this process has been connected with such negative phenomena as growing social

https://doi.org/10.11118/978-80-7509-820-7-0153 
inequalities, the development and use of new weapons or poisoning the environment, the latter of which was long ignored despite a strong evidence of a link between the destructive activity of mankind and the climate change, associated with increasing number of natural disasters claiming the lives of people and animals and causing destruction sometimes to a degree which causes the waves of the so-called "climate emigration". The climate change is also associated with military conflicts over various types of resources, including water, an example of which may be the tensions between Egypt and Ethiopia over the use of the Nile's water resources.

This state of affairs is forcing mankind to choose between continuing overexploitation and making profits at the expense of ever diminishing Earth's resources or radically changing the way of life, and adopting the idea sustainable development, which is not exactly a novelty because many advocated for a good treatment of the environment in the past; yet, these views frequently ignored. The contemporary situation is forcing to choose one of the two options mentioned above. In the context of huge ecological threats, this decision is connected with the question of the survival of mankind.

\section{Literature Review / Research Background}

The issues discussed in this article has yet to be described holistically (Singer 2017, pp. 216-255), and sustainable development is dominated by the tendency to adopt approaches which are rather atomistic than holistic, and which focus on relatively specific topics (Mambretti, Miralles i Garcia 2020). As a result, there are plenty of treatises and papers on detailed issues in the scientific literature, and very few generalizations that are valuable in terms of research. This is due to significant methodological differences rendering it impossible to arrive at conclusions that could not be reasonably questioned. There are many books on ecology, and also publications about the influence of ideology on the various types of mankind activity in the area of environment protection, but none publications satisfyingly presenting the challenges to sustainable development concept in the context of global economy (Cavanagh, Mander 2004, pp. 86-198).

An important role is played by the polemical literature, representing the attitudes of individual ideological directions to the subject of ecology (Steger 2009, pp. 94-95); it is worth indicating the currently published works of politiciansscientists on these issues, whose authors are seen, e.g. in the ranks of the green movement (Esguerra, Helmerich, Risse 2017, pp. 58-113). Interesting works include ideological texts, showing ambitions to give direction to the discussion about the essence of ecology and its impact on the existence of mankind, an example of which can be so-called "deep ecology"'(Lalenti 2020, pp. 13-188). Significant new impulses come from philosophical and ethical works, showing the moral aspects of this issue (Singer 2004, pp. 1-195). Valuable works are also created on the "periphery" of ecological topics, e.g. in the pedagogical context (Zielinski 2014, 
pp. 393-412). However, there are no texts presenting the processual character of creating sustainable development concept in the historical perspective in relation to the relevant challenges. This article tries to fill the existing gap in research evidenced by the content of the literature of the subject.

\section{Methodology}

The methodological aim of this article is to use the research techniques that allow the analysis of sustainable development issue in the processual context. (Dekking, Kraaikamp, Lopuhaä, Meester 2010, pp. 135-327) The specificity of this research field rendered it necessary to use several complementary methods (Kumar 2014, pp. 256-330), among others and apart from "standard techniques", like the documentary research method and the analysis of media content (Neuendorf 2002, p. 52), also the comparative historical research method (Weber 2009, pp. 81-167).

\section{Results}

Small problems with environment-unfriendly human behaviour occurred already at the hunter-gatherer stage when the growth of a homo sapiens population in a particular area resulted in the local extinction of plant and animal species.

As a rule, the consequences were not very serious because a human community which depleted natural riches too much in one area, solved this problem simply by migrating farther. (Livi-Bacci 2012, pp. 1-124)

The situation became far more complex after the first larger and more organized structures, called "river civilizations" (like in Mesopotamia), entered the stage. The people living there were dependent on the environment, and possible anomalies, including those which these very people were to blame for, might well threaten their lives and the existence of their whole states. The main "sin against the nature" was polluting soil and water by metallurgy, seen already during the Middle Ages. Among other, older (related to ancient times) examples of the extinction of some species, like the lion in North Africa, being the result of catching these animals for arena fights by the Romans, can be mentioned.

The cultures of Central and South America, in which metalworking techniques did not develop, also experienced environmental problems due to overpopulation and poor water management. (Murray 2017, pp. 167-177) It is also possible that the collapse of the irrigation system of Angkor Wat (in Cambodia), being one of the a major ecological disasters of the Middle Ages, was caused by similar events (Elias 2017, pp. 195-239).

A certain increase in the destruction of the environment in Europe is associated with a seventeenth-century economic concept, namely mercantilism. At that time, manufactories were established in such colonial powers as France or England and a great demand for raw materials to produce goods and means of transport was 
observed, which was mainly relevant to timber for building ships and houses in developing cities. Therefore, it was probably not a coincidence that the first person to have ever used the term "sustainable development", namely German Hans Carl von Carlowitz (1645-1714), was a forest resource manager; he coined this new term no later than in 1713. Carlowitz's concept assumed running a "rationally-oriented" economy, and there is nothing surprising in the fact that his ideas have been drawn upon by thinkers concerned about the bad state of the environment in the second half of the twentieth century.

The problems with the destruction of the environment by human behaviour arose on a massive scale at the end of the $18^{\text {th }}$ century, and that because of the "'industrial revolution', which is understood as a dynamic process of scientific, economic and social changes initiated by patenting the improvement in the steam engine by the Scottish engineer James Watt in 1769. As it was observed, this period was extremely important for the history of mankind and, to a large extent, shaped the modern civilization. Unfortunately, there were also serious 'dark sides' of it, and one of them was the pollution of the environment on a huge scale.

The economic boom that followed the World War II exacerbated the ecological problems of our planet as it was the armed forces and the defence industries that contributed to polluting the environment. Signs of an impending disaster began to appear. In this situation, the discussion on the limits of economic development gained a lot of momentum, and its subject was taken up by the Club of Rome, an international think tank, established in 1968 and dealing with global problems in the context of the environment. As a result of its the work, a document entitled 'Limits to Growth" was prepared and published by the Volkswagen Foundation in 1972. The conclusions contained therein that development "without limits" is not possible, and overexploitation takes place at the expense of future generation (Johnson, Turner 2016, pp. 263-267).

The thoughts contained in the document of the Club of Rome generated considerable resonance in various circles. The resulting "ferment" led to attempts to remedy the negative state of affairs, and the most significant of them was the report of the World Commission on Environment and Development, chaired by the Social Democratic Prime Minister of Norway, Gro Harlem Brundtland, which was published in 1987. This commission was established at the request of the General Assembly of the United Nations. In the final document of the Commission's work, sustainable development concept as a reasonable combination of economic activity with respect to the environment was formulated. As a result of this, it was believed that future generations should inherit the world in a "good shape"' (Steger 2009, pp. 22-25).

Analysing the causes of the progressive degradation of the environment, the Gro Harlem Brundtland Commission criticized the overexploitation of the Earth's natural resources by the so-called Western developed countries (Trafialek, 2010, pp. 304318). At the same time, it was indicated that the Third World was trying to imitate 
both the Western way of economic activity and its way of life, which led to an additional burden on the ecological system of our planet (Marshall 2016, pp. 43-61). In order to improve the state of the environment, it would be necessary to seek international solutions and work out a general system of economic activity, taking into account the interests of less developed countries in the context of implementing "'sustainable development" concept (Gilbert 2012, p. 19).

The present period of time seems to be favourable for activities aimed at improving ecological condition of the world according to the principles of sustainable development. It seems to be easier to mutually connect the different segments of the world economy, and owing to that fact undertaking pro-ecological initiatives in one sector is likely to cause similar phenomena in other parts of the global economy. Regardless of this, sustainable development faces many challenges hindering its implementation.

The most serious of those include the philosophy of maximizing profits 'at all costs', typical for laissez-faire capitalism and connected with the belief nothing matters more than continuous economic growth, which natural resources should serve.

A very serious challenge to sustainable development is poverty and large social differences prevailing in many parts of the world. Food shortage, clean water or housing makes people affected by these plights focus primarily on survival, while usually neglecting environmental problems. Ecological issues are not regarded as very important by the governments of poor countries either (Stiglitz 2016, pp. 284242).

The development of so-called "green technologies"' and their implementation in the industrial sector changes the structure of world's economies, and poses a significant problem for a large number of small and medium-sized companies, often dependent on larger economic entities. Organizations of this type are usually unable to develop innovative technologies or implement them effectively. This problem, as a rule, does not affect large companies having adequate dedicated funds, but it not so in the case of small and medium-sized enterprises. The same applies to transport, which is currently one of the largest sources of pollution of the environment. It is much easier to demonstrate innovation in the implementation of sustainable development concept for large companies, supported by local governments, as it is proved by, among others, the example of Hamburg-Holstein transport company (Verkehrsbetriebe Hamburg-Holstein) in Germany than smaller companies, which have to rely mainly on their own resources in terms of ecological activities.

Dangers to the implementation of sustainable development concept are related to the unclear forms of the operation of "great economic players", namely transnational corporations, whose financial potential often exceeds those of individual national economies. These above-mentioned business organizations largely set the direction for the world economy, and are able to effectively torpedo "ecological orientation" in their sphere of influence. In this respect, they could 
count on the solidarity of the conservative parts of the bureaucratic apparatuses in many countries, which seem to be reluctant to any changes considered to be too rapid and revolutionary (Pikketty 2014, pp. 237-467).

Serious challenges are related to political area; the fact that there are so many antagonisms between states or groups of states, sometimes reaching the level of armed conflicts, is not conducive to harmonious cooperation in the implementation of sustainable development concept. Although there is a certain rapprochement in this area, related to the experiences of "common interests" in the scope of halting the environmental disaster and avoiding the negative effects of the climate change, there is still so much uncertainty and mutual aversion among them. In this context, there are serious differences of interests between countries with certain types of economies, which, obviously, affect their activities in the field of nature conservation, should also be mentioned; an example may be the fact that countries with large oil resources strive to the use of energy from renewable sources. They are in natural opposition to these countries which do not have such resources and which are more interested in introducing solutions based upon energy from renewable sources.

Serious threats are related to nationalist sentiments, manifested, among others, by reluctance to take action in order to protect the environment when other countries fail to do so, be it really or allegedly. It is not surprising that such an attitude opens the "Pandora's box" of mutual accusations, and renders it impossible to undertake act for the benefit of the whole world. Practice shows that this practice is willingly resorted to by demagogues and autocrats.

A serious problem is created by the tendency to subsidize, in a more or less hidden way, certain types of energy or technological solutions harmful to nature and the use of "deceptive calculation systems", which fail to take into account the real losses associated with the removal of damage after specific practices within the scope of production or service. In this context, attention should be paid to the risks associated with pseudo-green activities, which do not actually help to protect the environment. A good example can be nuclear energy, praised by its supporters as the "'best solution to the energy crisis", apparently not realizing, or refusing at admit, that its "greenness" is simply a fake. Numerous accidents at nuclear power plants and the problems with the storage of radioactive waste from them, with a half-life period of many thousand years, can illustrate this state of affairs well (Adams, Anderson 2019, pp. 11-140).

In the field of agriculture, large food production corporations pollute the environment to a much greater extent than small farms. In many countries, such as Brazil, agricultural companies corrupt the authorities, and achieve profits at the expense of the environment.

There are also controversial projects such as the agricultural large-scale cultivation of plants (e.g. soybeans) used to produce fuel oils instead of food that deserve mentioning in this context. There can be serious doubts as to whether such 
projects will be good for the protection of the environment, considering the fact that the huge plantations of this kind threaten the existence of hundreds of thousands of farmers, and, simultaneously, consume enormous amounts of costly water.

Another serious challenge to sustainable development is greenwashing, which shows a phenomenal ability to adopt itself to new situations in order to deceive customers and "make money". This practice is difficult to combat, and it seems that as long as it finds a sufficient number of ignorant victims, it will not be abandoned or eradicated.

Sustainable development concept is faced also with the "basic existential challenge", and that means the shrinking resources of our planet along with the continuous growth in the Earth's population. It resulted in the necessity to change the people's way of life, in particular, to resign from practices that rob our planet of wealth and destroy the environment.

\section{Discussion}

In the past, the attitude based upon sustainable development was often contrasted with a free market economy concept. This way, some of the public arrived as a an opposite conjunctions, an antagonistic image was created: on the one hand, the activities of an economic nature, with an evident pursuit of profit, even at the expense of nature, and, on the other, pro-ecological activities, limiting the effectiveness of economic activity. (Hannerz 2010, pp. 13-102) Regardless of this, some big economic players tend to pose as "role models" in terms of "ecological cleanliness" in developed countries, while, at the same time, moving their manufactories based upon dirty technologies to developing countries (Cavanagh, Mander 2004, pp. 86-88) In this context, the well-known greenwashing phenomenon, based upon apparently pro-ecological activities, which, de facto, lead to gaining profits using a kind of spin techniques, seems debatable.

Another tendency that complicates the public discussion on ecology is its perception by some decision-makers mainly in the context of its economic components and in isolation from the social awareness indispensable if sustainable development is to receive supported by society it needs to be successful (Singer 2016, pp. 287-293).

The destruction of the environment forces us to take a rapid action, yet, as previously mentioned, not everyone shares this view. The opponents are not a homogeneous group, nor and their actions are not always driven solely by greed or opportunism. There are a large number of economic entities which, due to their behavior, may be defined as the "opponents" of the concept of sustainable development concept, although in the ideological sense they are not. These are mainly small and medium-sized firms that cannot afford to develop and implement expensive technological innovations to improve the condition of the environment. Considering the current economic structure of the world, it should be stated that this 
issue concerns a significant part of the economic organizations of our globe. (Acemoglu, Robinson 2013, pp. 70-95) Simultaneously, it is necessary to indicate the social differentiation in the context of the north-south division, which, to a large extent, still remains relevant. It seems that the lack of support for poorer economic sectors in the world may be one of the most important challenges for the implementation of sustainable development concept in general. It is closely related to the issue of education, especially, for the poorer part of the world population; not only does the lack of adequate efforts in this regard deprive huge numbers of young people of access to development opportunities, but also makes them undertake various forms of activity that harm the environment. The existing problems force the supporters of sustainable development to fight to achieve their goals. On the one hand, they have to deal with environments hostile toward them, but on the other, raising ecological awareness also means increasing support for them. Despite the existing difficulties, the chances of victory in the implementation of sustainable development concept are not small.

\section{Conclusion}

It took sustainable development concept a long time to take shape and gain supporters. Despite many efforts by its advocates, it did not succeed as, for a long time, it failed to obtain the necessary ' 'implementation power'. Finally, it began to take shape in the form of particular political decision reflected in specific documents as well as a broad movement for sustainable development. There are also discernible signs of a "green technological revolution" as manifested in the development of increasingly efficient renewable energy sources. Despite the difficulties, for the first time in the human history, there is a real possibility to take opportunity for collective action for sustainable development. To be effective, such an action must be collective, planned for a long time, and based upon a change in the way of thinking and living from "wasteful and selfish" to rational and dedicated to the common good of mankind. In shaping such attitudes, efficient scientific and educational institutions as well as strong cultural and opinion-forming centres are necessary (Akerlof, Shiller 2009, pp.19-25) Not only can they help create a positive social climate for the implementation of sustainable development, but also make more people understand that the actual battlefield between those caring about the environment and those disregarding its state. In the light of the above considerations, it seems to be possible. In this context, it is worth realizing the meaning of the words spoken many years ago by Mahatma Gandhi "'What we are doing to the forests of the world is but a mirror reflection of what we are doing to ourselves and to one another', and also "What we do today, is our future." 


\section{References}

1. .Acemoglu D., Robinson J.A., (2013), Why Nations Fail, Pofile Books, London.

2. Adams R.M., Anderson L. R., (2019), Policing in Natural Disasters, Temple University Press, Philadelphia, Rome, Tokyo.

3. Akerlof G. A., Shiller R. J., (2009), Animal Spirits, Princeton University Press, Princeton and Oxford.

4. Cavanagh, J., Mander, J., (2004), Alternatives to Economic Globalization, Berrett-Koehler Publishers, San Francisco.

5. Dekking F.M., Kraaikamp C., Lopuhaä H.P., Meester L.E., (2010), Spronger, Londom.

6. Elias N., (2017), The Civilizing Process, UK Blackwell Publishing, Oxford.

7. Esguerra A., Helmerich N., Risse T., (2017), Sustainability Politics and Limited Statehood Contesting the New Modes of Governance, Springer, e-book.

8. Gilbert M., (2012), European Integration, Roman \& LITTLEFIELD PUBLISHERS, INC.

9. Hannerz U., (2010), Anthropology's World, Pluto Press, New York.

10. Lalenti V., (2020), Deep Time Reckoning: How Future Thinking Can Help Earth Now, The MIT Press, London.

11. Livi-Bacci M., (2012), A Short History of Migration, Polity, Bologna.

12. Johnson D. Turner C., (2016), European Business, Routledge, London, New York.

13. Kumar R., (2014), Research Methodology, SAGE, London.

14. Mambretti S., Miralles i Garcia J. L., (2020), Urban Agriculture and City Sustainability II, London.

15. Marshall T., (2016), Prisoners of Geography, CPI Group (UK) Ltd., Croydon.

16. Murray D., (2017), The Strange Death of Europe, Bloomsbury, London.

17. Neuendorf K., (2002), The Content Analysis Guidebook, Sage Publications Thousand Oaks, CA.

18. Pikketty T., (2014), Capital in the Twenty-First Century, The Belknap Press of Harvard University Press, Cambridge, Massachusetts, London.

19. Singer P., (2016), A Companion to Ethics, Blackwell Publishing, Singapore.

20. Singer P., (2004), One World, Yale University Press, NewHaven\&London.

21. Singer P., (2017), Practical Ethics, Cambridge University Press, Cambridge.

22. Steger M. B., (2009), Globalization, Oxford University Press, Oxford.

23. Stiglitz J.E., (2016), The Great Divide, Penguin Book, Great Britain.

24. Trafialek, E., (2010), Education towards demographic old age (in:) Ekonomiczny, socjalny, ekologiczny kontekst współczesnych problemów międzynarodowych, Instytut Ekonomiczny Ukrainy, Winnica, pp. 304-318.

25. Weber M., (2009), Die protestantische Ethik, Anaconda, Köln.

26. Zielinski P., (2014), The Education of the Vietnamese Minority in Poland, Wydawnictwo Naukowe UAM, Studia Edukacyjne, 2014, nr 33, s. 393-412. 